\title{
Effect of Meditation on Stress Management of IBS Patients
}

\author{
Renu Tomer*, Dr. Mridula Sharma**
}

\section{ABSTRACT:}

Meditation is an intensely personal and spiritual experience. The purpose of meditation technique is to channel awareness in positive direction by concentrating on inner self. A study was carried out to study the effect of meditation on stress management of IBS patients. Stress management scale constructed by Singh and Srivastava was administrated to patients consisted of 80 IBS patients of between age group of 20-40 years,2 groups were taken one -who meditated (experimental group ) and one who did not meditate (controlled group ). For analysis of data t-test is run. Result showed that patients showed better stress management in the group of patients who meditated in comparison to controlled group who did not meditate.

Keywords: Meditation, Stress Management, IBS

\section{INTRODUCTION}

Stress has become part and parcel of human life. It is an emotional intellectual or physical response to an internal or external change, demand or pressure. Stress can come from any situation or thought that makes one feel frustrated, angry, nervous, or anxious (Angela marrow, 2011). It is a general term applied to various mental and physiological pressures experienced by people . Physical response to stressful situations can include "butterflies" in the stomach or the sudden urge to have a bowel movement. Stress can also cause diarrhea or constipation. It affects the function of the colon. Stress can play a large role in IBS because the syndrome has been linked to brain gut dysfunction a break down in brain's ability to control the gastrointestinal function. The colon is governed by autonomic nervous system, the same system the controls heart and lungs, and that system can be affected by emotional state. Stress related IBS is irritable bowel syndrome that has either been caused by or made worse by a person's stress or anxiety. Drossman (2011) found that IBS sufferers tend to have a lower threshold for coping with stressful situations and are more likely to react to negative events that in turn, can have catastrophic effects on the working of the gut. Irritable Bowel Syndromes (IBS) is a functional gastrointestinal (GI) disorder, meaning it is a problem caused by changes in how the GI tract works. People with a functional GI disorder have frequent symptoms, but the GI tract does not become damaged. IBS is not a disease; it is a group of symptoms that occur together. Symptoms of IBS are abdominal pain, Diarrhea constipation.

\footnotetext{
*Research Scholar, Department of Psychology, Meerut College, Meerut

**Reader, Department of Psychology, Meerut College, Meerut
}

(C) 2014 R Tomer, M Sharma; licensee IJIP. This is an Open Access Research distributed under the terms of the Creative Commons Attribution License (http://creativecommons.org/licenses/by/2.0), which permits unrestricted use, distribution, and reproduction in any Medium, provided the original work is properly cited. 
Stress management encompasses techniques intended to equip a person's with effective coping mechanisms for dealing with psychological stress, with stress defined as a person's physiological response to an internal or external stimulus that triggers the fight or flight response. Stress management is effective when a person utilizes strategies to cope with or alter stressful situation. It refers to a wide spectrum of techniques and psychotherapies aimed at controlling a person's levels of stress, especially chronic stress, usually for the purpose of improving everyday functioning. The level of chronic life stress threat predicts the clinical outcomes in most patients with IBS. (J.E. Kellow, 1998). Reducing stress is an important step in getting IBS symptoms under control. Stress, emotional or physical, is a common trigger which worsens the digestive problems of IBS. In people with IBS, the intestines seem to be extra sensitive to stressful situations and feeling. "That overreaction" can trigger or worsen the digestive problems of IBS.

Meditation is known for improving body luster and general health blood flow increase oxygen and Nutrient flow to cells and tissues. It can help to resolve deep neuroses, fears and conflict which play a role in causing distress and ill health. Meditation can be effective form of stress reduction and has the potential to improve quality of life and decrease health care costs. It involves achieving a state of "thoughtless awareness" in which the excessive stress producing activity of the mind is neutralized without reducing alertness and effectiveness. Dealing with irritable bowel syndromes (IBS) is not easy, but the stress (and the symptoms) involved may be lessened with mind fullness meditation. Chapel Hill (2009) presented a study showing that women with irritable bowel syndrome were able to reduce their symptoms by 38 percent with mindfulness meditation compared to only a 12 percent reduction for women who took part in a support group. Diana (2010) found that meditation has beneficial effect on health. It can relieve mental and physical stress and by extension, help with common stress related illness, including IBS. David (2012) support the concept that irritable bowel syndrome (IBS) is a biopsychosocial disorder that can be explained by a neurobiological model which postulates stress-induced alterations in central stress and arousal circuits and activation of parallel motor outputs from brain regions that can affect bodily function and behavior.

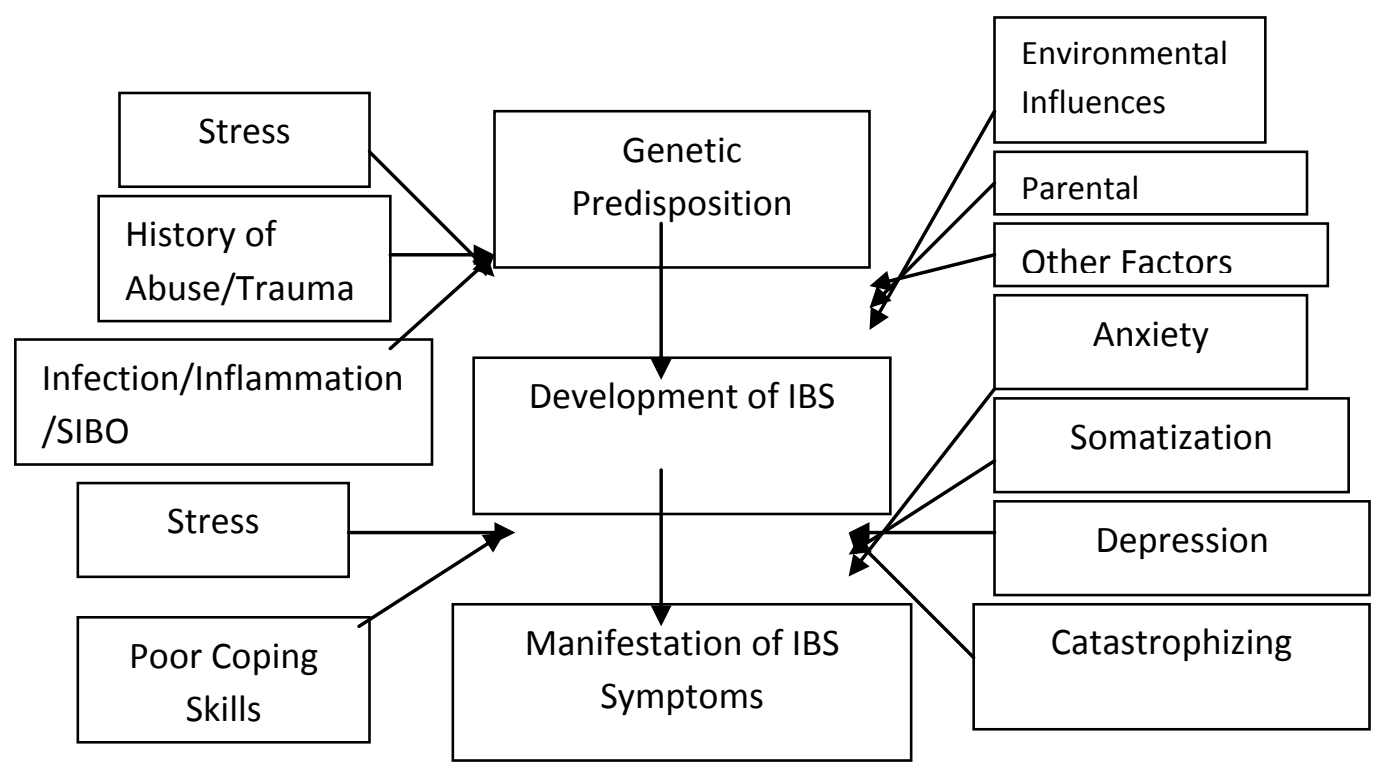


Cathy Wong published a study (2001), IBS patient who underwent six weeks of meditation training experienced significant improvement in several IBS symptoms. (Including diarrhea and bloating). The meditation technique involved initiating the relaxation response, and participants were asked to practice twice a day for 15 minutes.

\section{METHOD}

PURPOSE: The purpose of the present study was to study the effect of meditation on stress management of IBS patients.

OBJECTIVES: In the present research investigation, we tried to achieve the following objectives.

- To study the effect of meditation on stress management of IBS patients.

- To study the effect of meditation on stress management

- To study the effect of meditation on IBS patients.

HYPOTHESIS: Keeping in mind the objectives of the present study the following hypothesis was proposed for the investigation empirical verification.

- There will be significant effect of meditation on stress management of IBS patients.

- There will be significant effect of meditation on stress management.

- There will be significant effect of meditation on IBS patients.

DESIGN: In the present study experimental design was used to complete the research work.

VARIABLES: $\quad$ I.V. Meditation

\section{D.V. - Stress management IBS Patients}

SAMPLE: A sample comprised of 80 IBS patients of age group 20-40 years. 40 patients were mediators (controlled group) \& 40 patients were non-mediators (experimental group). Subject was selected through purposive sampling.

TOOLS: For the measurement of stress management scale constructed by Singh and Srivastva.

Procedure: The IBS patients who come to tertiary centre we established good rapport with them. The stress management scale was distributed to IBS patients who are meditators and Non meditators. The Instruction were given to the patients regarding the scale. The patients were requested to clear their doubts, if any. After this, the scale was taken back from all the patients. In the end, thanks were paid to all subjects for providing valuable time. 
RESULT: Obtained data were analyzed with the help of mean and t-test.

Table-1, Mean Scores of Stress Management for IBS Patients

\begin{tabular}{|c|c|c|c|}
\hline Group & N & Scores & Mean \\
\hline Meditators & 40 & 4399 & 109.7 \\
\hline Non-Meditators & 40 & 3979 & 99.47 \\
\hline
\end{tabular}

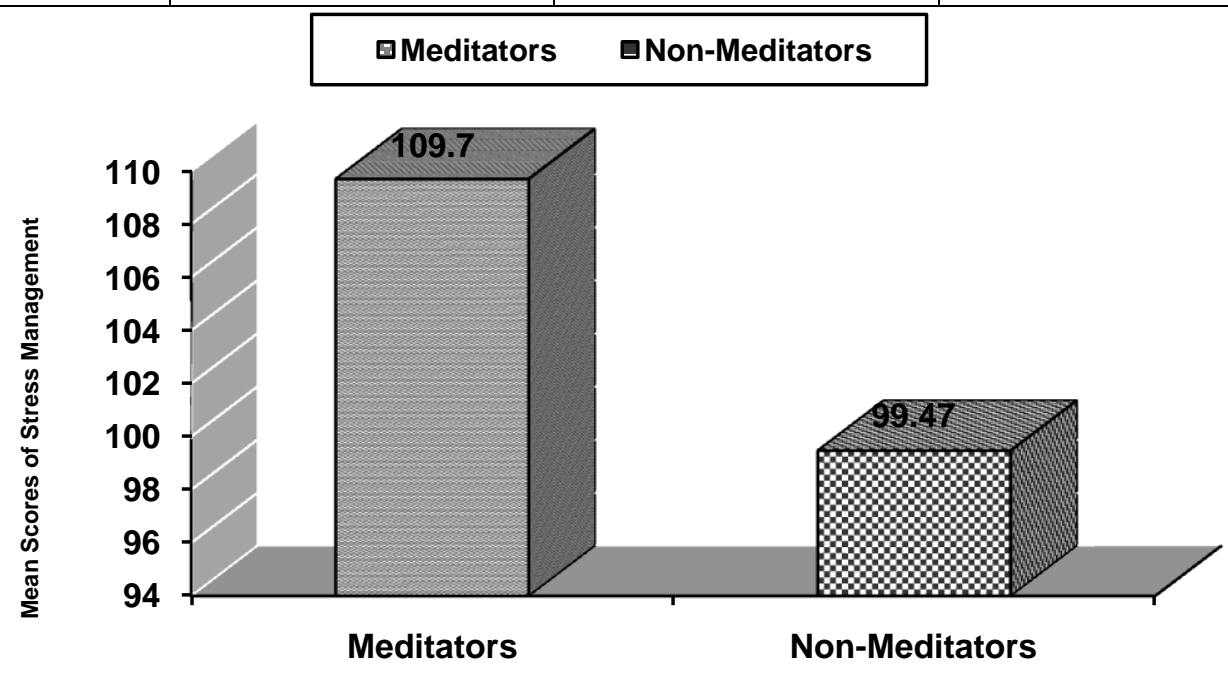

Table 1, indicate that meditators shows highest stress management scores while non meditators shows lowest stress management scores. This quite clearly reveals that the patients with IBS have more stress management who are meditators in compare to non meditators. It signifies that meditators have high stress management.

Table-2, t-value of Stress Management for IBS Patients

\begin{tabular}{|c|c|c|}
\hline $\mathbf{S E}_{\mathbf{D}}$ & Critical Value & t-value \\
\hline 1.94 & 2.64 & 5.27 \\
\hline
\end{tabular}

Table 2 shows that $\mathrm{t}$-value between meditators and non meditators with IBS are 5.27 which is greater than the table value (2.64) at 0.01 level. It suggests that meditation have significant effect on stress management of IBS patients. 


\section{DISCUSSION AND CONCLUSION}

The purpose of the present study was to study the effect of meditation on stress management of IBS patients. The significant $t$-value indicates that meditation significantly effects the stress management in IBS patients. Thus, the hypothesis that there will be significant effect of meditation on stress management of IBS patients.

Renee Green (2011) insist that IBS does not lead to serious disease but does cause extreme discomfort and distress for suffers. Controlling the symptoms is the key to managing IBS, but some people find it disabling. Besides traditional remedies, some suffers have found help in managing the distress by using meditational therapy. Barbara (2011) founded that physical and psychological symptoms of IBS were more effectively managed by people practicing mindfulness meditation than in support group therapy. Mindfulness meditation costs nothing but time, offers a wide range of emotional and physical benefits, and does not appear to carry any risk of unwanted side effects. Meditation helps people to change their negative environment conditions. Practicing meditation to help digestion by alleviating anxiety and stress is bringing benefits to people worldwide. Techniques for meditation to help digestion.

To conclude it can be said that mediation has a significant effect on stress management of IBS patients. IBS patients have proneness towards stress. Meditation offers a management solution to IBS sufferers. This study has been conducted on a small sample in order to get better results the researchers suggest that study to conducted on larger sample with more constructive meditation technique.

\section{REFERENCES}

1. Barbara (2011). Meditation Relieves IBS Severity. Retrieved Nov 29, 2012 http://www.nccam.nih.gov.

2. David (2012). IBS and Stress. Retrieved Sep, 2012 http://www.nebi.nim.nin.gov/pubmed

3. Diana (2010). Mindful Meditation for IBS. Retrieved Nov 29, 2012 http://www.enwikipedia.org

4. Drossman. (2011) Stress Management for IBS Retrieved Nov 28, 2012 http://www.drweilblog.com

5. Greene, R. (2011). Meditation for Irritable Bowel Syndrome Retrieved. Nov 29, 2012 http://www.ehow.com

6. Hill, C. (2009). University of North Carolina. Mindfulness Meditation Retrieved, Nov 28, 2012 http://www.wildmind.org

7. Kellow, J.E. (1998). Stress Management Retrieved. Nov. 29,2012 http://www.gastroendonews.com 
8. Marrow, A. (2011). Stress and IBS Retrieved Nov 28, 2012 http://www.ibsresearchupdate.org.

9. Thompson, D. (2010) How Stress Affects Irritable Bowel Syndromes Retrieved, Nov 28, 2012. http://www.everdayhealth.com.

10. Wong, (2013). Irritable Bowel syndrome and Stress. Retrieved Jan 18, 2013. http://www.altmedicine.com. 